\title{
Carotid Intima-Media Thickness (CIMT), Hypertension, and CVD Event
}

Nur Samsu ${ }^{1}$

${ }^{1}$ Division of Nephrology and Hypertension, Department of Internal Medicine, Faculty of Medicine, Universitas Brawijaya, dr.Saiful Anwar General Hospital, Malang.

Corresponding Author:

Nur Samsu,

Division of Nephrology and Hypertension, Department of Internal Medicine, Faculty of Medicine, dr. Saiful Anwar-General Hospital, Malang. Jl. Jaksa Agung Suprapto No. 2, Malang 65112, East Java - Indonesia. Email: nur_samsu.fk@ub.ac.id

The majority of studies indicated that elevated levels of established cardiovascular risk factors, such as age, sex, total cholesterol, LDL cholesterol, systolic blood pressure, body mass index, and a decrease in HDL cholesterol, are associated with an increased CIMT in a graded manner.

Hypertension is an important risk factor for cardiovascular complications, especially stroke.[1] Hypertension also has an important complex role in the pathogenesis of atherosclerosis. A continual elevated in blood pressure caused changes in vascular endothelial function, such as increased vascular permeability, decreased endothelial vasodilators, and increased adherence of leukocytes on the surface of the endothelium to the accumulation of macrophages in the intima layer.[2] Hypertension also increases vascular smooth muscle cell (VSMC) proliferation. On the other hand, inflammation and endothelial dysfunction also play a critical role in the pathogenesis of hypertension. ${ }^{[3]}$ Isolated systolic hypertension with elevated pulse pressure is an indication of blood vessel stiffness, that can be considered as a marker of atherosclerosis. Several studies have shown a correlation between hypertension and CIMT thickness and blood vessel stiffness. [4] [5]

\section{Is the increase in CIMT related to an increase in CVD events?}

Based on many studies, both cross sectional and longitudinal, it has been proven that carotid intima-media thickness (CIMT) predicts cardiovascular events (CVD) and welldescribed surrogate marker for cardiovascular risk. According to review by Yokoyama et al., a thickened CIMT correlates with the presence of myocardial infarction and stroke by crosssectional analysis. Several prospective studies have shown an association between increased CIMT and the incidence of cardiovascular disease in the general population with or without prior cardiovascular disease. CIMT is significantly higher in diabetic patients than in nondiabetic subjects, and an increased CIMT is associated with angiography-evaluated coronary artery disease and predicts future events of silent brain infarction and coronary heart disease in type 2 diabetic subjects. ${ }^{6]}$

\section{Can antihypertensive drugs reduce the thickness of the CIMT?}

Hypertension has been associated with atherosclerosis and cardiovascular disease. Carotid intima media thickness is increased in hypertensive patients. But, the correlation between carotid intima media thickness and antihypertensive agents is still uncertain.

An observational cohort study of 1809 patients showed that 1079 hypertensive patients had a thicker CIMT that was thicker than non-hypertensive patients, with CIMT of $(0.72 \pm 17 \mathrm{~mm}$ vs $0.64 \pm 15 \mathrm{~mm}, \mathrm{P}<.001)$, $(0.31 \pm 0.07 \mathrm{~mm}$ vs $0.30 \pm 0.06 \mathrm{~mm}, P<.001)$, and $(0.41 \pm 0.13 \mathrm{~mm} \quad$ vs $0.35 \pm 0.12 \mathrm{~mm}, \mathrm{P}<$ $.001)$. Additionally, hypertensive patients on beta-blockers also had thicker CIMT than the non-beta-blocker group, with CIMT of 
$(0.74 \pm 0.18 \mathrm{~mm}$ vs $0.71 \pm 0.16 \mathrm{~mm}, \mathrm{p}=0.018)$, $(0.33 \pm 0.09 \mathrm{~mm}$ vs $0.31 \pm 0.07 \mathrm{~mm}$,

$p=0.029), \quad$ and $\quad(0.43 \pm 0.13 \mathrm{~mm} \quad$ vs $0.40 \pm 0.13 \mathrm{~mm}, p=0.035)$. Multivariate analysis showed that CIMT was only correlated with betablockers $(\mathrm{OR}=2.489, \mathrm{CI}=1.183-5.239, \mathrm{p}=0.016)$. This study showed that beta-blocker could be associated with increased carotid wall thickness as well. [7]

Other study showed that enalapril (10 $\mathrm{mg} / \mathrm{d}$ ), reduced CIMT thickening by $0.01 \mathrm{~mm} / \mathrm{y}$. Half of the patients in this 2-year follow-up study had antihypertensive agents at baseline, and additional treatment with enalapril did not lower systemic blood pressure levels; therefore, the reduction of CIMT appeared independent of a blood pressure-lowering effect. ${ }^{[8]}$ This is likely because of their anti-inflammatory effect of ACE-inhibitor by suppressing generation of reactive oxygen species in humans. ${ }^{[9]}$

Results study by Tantri NL et al., one of the articles in the current edition, showed that there was a significant difference in CIMT between control group and therapy group (ACE-I or CCB), and treatment with amlodipine (CCB) showed the lowest CIMT but not significantly different compared to the ACE-I therapy group $(0.69 \pm 0.02$ vs $0.86 \pm 0.06, p=0.879$ ). Meta-analysis of 5 trials with a total of 287 patients comparing ACE inhibitors with CCBs. Mean IMT at baseline ranged from 702 to $1038 \mu \mathrm{m}$. Compared with ACE inhibitors, CCBs significantly reduced the yearly increased in carotid IMT by $23 \mu \mathrm{m}$ ( $95 \% \mathrm{CI}:-42$ to $-4 ; \mathrm{p}=0.02$ ). CCB seems having more impact on CIMT regression, possibly related to the effects of amlodipine on vascular smooth muscle proliferation, as research conducted by Lai et al. on VSMC culture in hypertensive rats. Amlodipine can inhibit DNA synthesis and VSMC proliferation by evaluating the growth factor expression impact, phenotype changes, and vascular smooth muscle cell (VSMC) proliferation in hypertensive rats. Amlodipine can inhibit the expression of PDGF, TGF- $\beta 1$, and basic FGF, also mRNAs in VSMCs of hypertensive rats. Amlodipine inhibits the marker expression of osteopontin synthesis phenotypes and Gla mRNAs matrix, which shows the process of inhibiting VSMC growth and changing contractile phenotypes into synthetic phenotypes.[10] Based on the research results of Lai et al, it can be assumed that the antiproliferative effect of amlodipine is not associated with a decrease in blood pressure.

\section{Is CIMT regression associated with a reduction in cardiovascular events?}

It is well known that there is a positive correlation between CIMT and CVD events. Increased carotid IMT is associated with an increased risk of coronary heart disease (CHD) and cerebrovascular events (CBV). There are still questions, does the favorable changes of IMT reflect prognostic benefits or have clinical usefulness? what are the changes in CIMT that result from therapies correlate with nonfatal myocardial infarction (MI)?

Information regarding the potential of regression (or diminished progression) of CIMT for reduction of cardiovascular events is still limited. In a meta-regression analysis of 15.598 patients, it was documented that regression in CIMT progress between activetreatment (antihypertensive, antidiabetic, or lipid-lowering) and placebo groups was associated with a greater risk of myocardial infarction in the placebo-arm. Specifically, every $0.01 \mathrm{~mm} / \mathrm{y}$ regression in CIMT features a lower risk of myocardial infarction (odds ratio [OR]: 0.82; 95\% CI: 0.69 to 0.96$).{ }^{[11]}$

On the other hand, based on another meta-regression analysis of 41 involving 18,307 participants, it was concluded that there was no significant relationship between IMT regression and CHD events (Tau 0.91, $\mathrm{p}=0.37$ ), CBV events (Tau -0.32, $\mathrm{p}=0.75$ ), and all- cause death (Tau -0.41, $\mathrm{p}=0.69$ ). In addition, subjects' baseline characteristics, cardiovascular risk profile, IMT at baseline, follow-up, and quality of the trials did not significantly influence the association between IMT changes and clinical outcomes. regression or slowed progression of carotid IMT, induced by cardiovascular drug therapies, do not reflect reduction in cardiovascular events. ${ }^{[12]}$

Another study involved 14 populationbased cohorts with 45,828 individuals. During a median follow-up of 11 years, 4007 first-time MIs or strokes occurred. Refitted the risk factors of the Framingham Risk Score and then extended the model with common CIMT measurements to estimate the absolute 10year risks to develop a first-time MI or stroke in both models. The $\mathrm{C}$ statistic of both models was 
similar (0.757; 95\% CI, 0.749-0.764; and 0.759; 95\% CI, 0.752-0.766). The net reclassification improvement with the addition of common CIMT was small $(0.8 \%$; $95 \%$ CI, $0.1 \%$ -

$1.6 \%)$. In those at intermediate risk, the net reclassification improvement was $3.6 \%$ in all individuals (95\% CI, 2.7\%-4.6\%) and no differences between men and women. It was concluded that the addition of common CIMT measurements to the Framingham Risk Score was associated with small improvement in 10-year risk prediction of first-time myocardial infarction or stroke, but this improvement is unlikely to be of clinical importance.[13]

More recent study in 31 cohort studies with 2 CIMT scans (total $n=89070$ ) on average 3.6 years apart and clinical follow-up, sub-cohorts were drawn: (A) individuals with at least 3 cardiovascular risk factors without previous CVD events, (B) individuals with carotid plaques without previous CVD events, and (C) individuals with previous CVD events. There are endpoint events in groups A, B and C, which are 3483, 2845 and 1165, respectively. Average common CIMT was $0.79 \mathrm{~mm} \pm 0.16 \mathrm{~mm}$, and annual common CIMT change was $0.01 \mathrm{~mm} \pm 0.07 \mathrm{~mm}$, both in group A. The pooled HR per SD of annual common CIMT change ( 0.02 to $0.43 \mathrm{~mm}$ ) was 0.99 ( $95 \% \mathrm{CI}$ : $0.95-$ 1.02) in group $A, 0.98$ (0.93-1.04) in group $B$, and 0.95 (0.89-1.04) in group C. The HR per SD of common CIMT (average of the first and the second CIMT scan, 0.09 to $0.75 \mathrm{~mm}$ ) was 1.15 (1.07-1.23) in group A, 1.13 (1.05-1.22) in group B, and 1.12 (1.05-1.20) in group C. It was concluded thatCIMT change does not relate to future risk events in highrisk individuals.[14]

Several hypotheses have been suggested to explain this discrepancy. One credible argument is that the small CIMT change, assessed with reasonable to considerable measurement error in cohort studies, and the low event risk in the asymptomatic general population make it difficult to discern such association.[15]

\section{R E F E R E N C E S}

1. Lawes CMM, Bennett DA, Feigin VL, and Rodgers A. Blood Pressure and Stroke: An Overview of Published Reviews. Stroke. 2004; 35:776-785. https://doi.org/10.1161/01.STR.0000116869.647 $\underline{71.5 \mathrm{~A}}$

2. Christopher G and Joseph W. Atherosclerosis: The Road Ahead. Cell. 2001; 104(4):503-516. https://doi.org/10.1016/s0092-8674(01)00238$\underline{0 .}$
3. Spieker LE, Noll G, Ruschitzka FT, Maier W, and T Lüscher. Working under pressure: The vascular endothelium in arterial hypertension. Journal of human hypertension. 2002; 14 . 617-630. https://doi.org/10.1038/sj.jhh.1001012.

4. Zanchetti A, Hennig M, Hollweck R, et al. Baseline Values but Not Treatment-Induced Changes in Carotid Intima-Media Thickness Predict Incident Cardiovascular Events in Treated Hypertensive Patients Findings in the European Lacidipine Study on Atherosclerosis (ELSA). Circulation. 2009, 120(12):1084-1090.

https://doi.org/10.1161/CIRCULATIONAHA.108.7 7311'

5. Okazaki S, Furukado S, Abe Y et al. Association of Inflammatory Markers and Carotid Intima-Media Thickness with the Risk of Cardiovascular Events in High-Risk Patients.

CerebrovascDis.2010;30(2):180-187.

https://doi.org/10.1159/000317106.

6. Yokoyama H, Katakami N, and Yamasaki Y. Recent Advances of Intervention to Inhibit Progression of Carotid Intima-Media Thickness in Patients With Type 2 Diabetes Mellitus. Stroke. 2006;37:24202427.

https://doi.org/10.1161/01.STR.0000236632.583 23.cd

7. Kim KH and Song IG Kwon TG. Impact of different antihypertensives on carotid arterial wall thickness. J Clin Hypertens. 2018;20:248-254. https://doi.org/10.1111/jch.13189

8. Hosomi N, Mizushige K, Oyama $\mathrm{H}$ et al. Angiotensinconverting enzyme inhibition with enalapril slows progressive intima-media thickening of the common carotid artery in patients with non-insulindependent diabetes mellitus. Stroke. 2001; 32: 1539-1545.

9. Dandona P, Kumar V, Aljada A et al. Angiotensin II receptor blocker valsartan suppresses reactive oxygen species generation in leukocytes, nuclear factor- $\kappa \mathrm{B}$, in

mononuclear cells of normal subjects: evidence of an anti-inflammatory action. J Clin Endocrinol Metab. 2003; 88: 4496-4501.

10. Lai YM, Fukuda N, Su JZ et al. Novel Mechanisms of the Antiproliferative Effects of Amlodipine in Vascular Smooth Muscle Cells from Spontaneously Hypertensive Rats. Hypertens Res. 2002; 25(1):109115. https://doi.org/10.1291/hypres.25.109.

11. Goldberger ZD, Valle JA, Dandekar VK, Chan PS, Ko DT, and Nallamothu BK. Are changes in carotid intima-media thickness related to risk of nonfatal myocardial infarction? A critical review and metaregression analysis. Am. Heart J. 2010;160: 701714. doi: 10.1016/j.ahj.2010.06.029.

12. Costanzo P, Perrone-Filardi P, Vassallo E et al. Does carotid intima-media thickness regression predict reduction of cardiovascular events? A meta-analysis 
of 41 randomized trials. J. Am. Coll. Cardiol. 2010;56: 2006-2020. doi: 10.1016/j.jacc.2010.05.059.

13. Den Ruijter HM, Peters SAE, Anderson TJ et al. Common carotid intima-media thickness measurements in cardiovascular risk prediction: a meta-analysis. JAMA 2012;308: 796-803. doi: 10.1001/jama.2012.9630.

14. Lorenz MW, Gao L, Ziegelbauer K, Norata GD et al. Predictive value for cardiovascular events of common carotid intima media thickness and its rate of change in individuals at high cardiovascular risk - Results from the PROG-IMT collaboration. Plos One. 2018; 13(4): e0191172. doi: 10.1371/journal.pone.0191172.

15. Wang JG, Staessen JA, Li Y et al. Carotid Intima-Media Thickness and Antihypertensive Treatment A Meta- Analysis of Randomized Controlled Trials. Stroke. 2006; 37(7):19331940.

https://doi.org/10.1161/01.STR.0000227223.90 $\underline{23} \underline{9.13}$.

\section{Cite this as:}

Samsu N. Carotid Intima-Media

Thickness (CIMT), Hypertension, and CVD Event. Clinical and

Research Journal in Internal

Medicine, 1.1 (2020): 1-4.

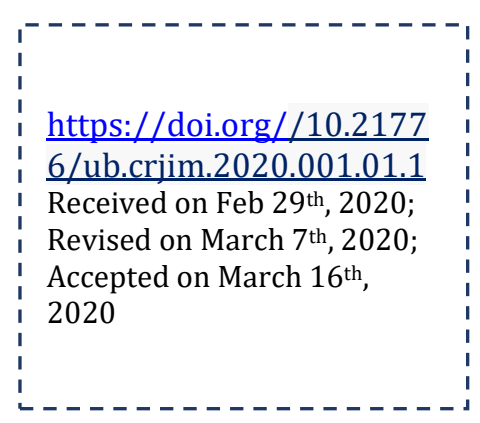

